\title{
Designing Design Team Experiences: Creating STeamER
}

\author{
Carolyn MacGregor, Taneem Talukdar, Jasvir Bains, and Jason Jo \\ Department of Systems Design Engineering \\ University of Waterloo, Waterloo ON N2L 3G1 \\ Contact: cgmacgre@uwaterloo.ca
}

\begin{abstract}
A challenge in teaching engineering design lies in guiding the collaboration of students in a design team environment. We have identified a need for a virtual design space application that enhances the user experience so as to encourage teamwork and project management skills. The Student Team Electronic Resource (STeamER) project arose out of lessons learned over the past nine years teaching project-based design courses to engineering students. The overall objective of STeamER is to support students and instructors involved in team-based projects. We describe the rationale as well as identified requirements for the STteamER application.
\end{abstract}

\section{Introduction}

For the past few years, engineering educators have been encouraged by industry to help students develop teamwork skills in preparation for the realities and demands of commercial and industrial design. As more business and industry move towards globalization a key for success is a company's ability to remain agile (i.e. the ability to reconfigure and maximize personnel and technology to address pressing business requirements and product solutions) [1]. Workers are expected to be flexible in terms of their abilities to integrate with and adapt to changing work teams. Furthermore, team members may have to do a large portion of their communication and collaboration remote from one another.

A recent survey by the Canadian Council of Professional Engineers focused on the engineering practices of its members since 1999. At least 80 per cent of the respondents indicated that they have been involved in job-related team work [2]. While many find themselves working in close collaboration with others, most members of design teams have not been formally trained to collaborate and most businesses do not have the internal resources to do such training [3]. Employers now want engineering graduates to come equipped with technical skills as well as with soft skills in areas such as communication, ethics and professionalism, project management, team building and teamwork [4; 5]. Identified competencies associated with teamwork include: 1) clearly defining project goals of the team, 2) establishing and performing allocated tasks, 3) creating and maintaining a supportive team culture, 4) effective planning and time management, 5) implementing operating procedures to ensure effective team interactions, and 6) establishing incentives and rewards for team and individual achievement [6]. In the USA, the establishment of the ABET EC2000 criteria requires engineering programs to demonstrate that their graduates can function on multidisciplinary teams [7]. Although teamwork is not a mandatory educational objective set by the Canadian Engineering Accreditation Board, it is seen as a potential side benefit to the senior undergraduate design experience “... which preferably gives students an exposure to the concepts of team work and project management” [8, p.14]. Mindful of the need for team work exposure and training, engineering educators are making an effort to include student design projects as part of the first year engineering curriculum $[9 ; 10 ; 11]$.

\section{What does this mean for instructors?}

In order to develop the so-called soft skills, it is best to practice them in a realistic setting [4]. Teaching team work skills separate from a team-based 
project is unlikely to get committed participation from students. The design project is a natural vehicle for incorporating team experiences. However, many programs do not include formal design projects as part of the curriculum until the senior year. If teamwork skills take time to mature then leaving such education to the final year does not allow students much time to develop these skills or test their reliability on a different project before heading out into the workplace. It would seem reasonable to look for earlier opportunities to incorporate soft skills into the engineering curriculum.

All team projects have deliverables associated with them (e.g. proposals, prototypes, specifications, technical reports, etc.) We often think of the deliverables in terms of what the students need to deliver; but the instructor must also meet deliverables in order to address students' concerns. The higher the value of the team project as part of the overall course grade, the greater the concerns raised by the students as to how they will successfully meet the project goals. Students often raise their concerns in the form of questions, and these questions serve to identify their needs that must be addressed by the instructor.

The main concerns expressed by students are:

- How are we going to get work done outside of class time? (Need for Collaboration)

- How will we know what to do and when? (Need for Guidance and Project Management)

- How will we know we are on the right track? (Need for Feedback)

- What do we do if something goes wrong? (Need for Teamwork Rules and Procedures)

For the instructor, the modification of traditional group assignments to team learning experiences requires some devoted class time for training teams and setting expectations for teamwork, monitoring team project progress on a regular basis, and preparing methods of evaluation for both the team and the individual student. Such additions in seniorlevel courses have lead to measurable improvements in the quality of technical skills as well as improvements in team skills and attitudes towards teamwork [13]. Based on ten years of experience teaching engineering design courses, we have found that the time that an instructor must devote to projectbased courses for lower-level students can be substantial.

For example, in our Introduction to Systems Design Engineering, at the University of Waterloo, 90 first year students are required to carry out a term long design project in addition to attending regular course lectures on engineering design principles, design approaches, workplace safety, engineering ethics, and professionalism, as well as writing open-book exams. For the design project, students are assigned to 15-16 teams and have instructor-set delivery dates for the following: a formal design proposal (including a literature and patent review, as well as a budget and project schedule), a low-fidelity (non-functional) prototype, a medium-fidelity (semi-functional) prototype, a high fidelity prototype (fully functional), and a final technical report (including design specifications and drawings, as well as a report of allocation of team responsibilities and team learning). In addition, each student is required to keep an engineering design logbook to record his or her personal contributions and reflections on the design solution and process. On top of the design project deliverables, each team must deal with the intangibles of developing teamwork skills such as setting team norms, collaborative decision-making, and, invariably, conflict resolution. A conservative estimate for a course of this nature in terms of the time put in by the instructor and five teaching assistants on student contact and meetings; marking of deliverables; and providing team and individual feedback is in excess of 200 hours. This amount of time can be daunting to novice instructors, and even for seasoned professors, who are trying to juggle research and service along with their teaching loads.

We could abandon the student project or cut back on opportunities to interact with the students or to provide feedback; but we feel that the students would be the ones who would lose in the long run. Instead we have decided to capitalize on our experiences and attempt to design an electronic resource that will aid with team feedback and promote collaboration. The project is called STeamER (Student Team Electronic Resource); and is funded through a Learning Technology Innovation grant from the University of Waterloo's Centre for Learning \& Teaching Through Technology (LT3).

\subsection{Overview of SteamER}

The SteamER project received funding late Fall 2004. Since that point we have set up a small design team to begin the preliminary work on the design concepts for the SteamER software application. The design team consists of an experienced design educator and 4-6 undergraduate students with varying degrees of experience in terms of working in design teams, usability testing and evaluation, and software design and development. The team met regularly from January to April of 2004 to conduct task analyses on the roles played by students and instructors in projectbased courses and to brainstorm concepts for the 
student and instructor interfaces. Preliminary interface prototypes were developed for the student interfaces, and focus groups activities were conducted with 20 undergraduate students from Engineering and Kinesiology participating in a third year engineering technical elective on user-centred design. Since the design concepts for the interfaces are still in the preliminary stages, we will present, instead, the rationale for a software application to help mediate team work.

\section{Why focus on a technology-mediated solution?}

Providing engineering students with skills in technology- mediated collaboration should help them to adapt to agile business environments [1]. Technology-mediated solutions range from conference calls to exchange of email messages with document attachments, to live on-line chat sessions, to secured internet-based environments that allow for the posting of team messages and documents. Email-only solutions make it difficult for team members to keep track of the latest version of a team documents and communications. In addition, instructors may find that they are either being flooded with project-related emails if they are on every team's distribution list - or the other extreme - not kept apprised of team communications until a team is in crisis. On-line chat sessions may work well for informal communication between team members, but are not practical from a course management perspective. In addition, students have expressed concern over the prospects of instructors monitoring informal on-line communications.

Typical third-party sites used by student teams (e.g. eproject ${ }^{\mathrm{TM}}$; Yahoo! ${ }^{\circledR}$ groups) require that the individual team members register with the site. While this may be convenient for members of a single team, an instructor trying to monitor more than one team must be a member of each individual team with its own password and controls. In addition, such thirdparty solutions do not allow members of different teams to easily view or provide feedback on the efforts of another team.

The University of Waterloo has a secured central internet-based course environment, currently known as the University of Waterloo On-Line Environment (UWOne). Students of a course can log in to the central system for UWOne and view all of their courses that have on-line components. This has the advantage of having a familiar interface for courses and eases work flow for students who are trying to keep up with assignments in more than one course. Within UWOne, instructors can make available to students such things as course notes, lecture slides, assignments, quizzes, surveys, discussion boards, and drop-boxes for electronic submissions. Instructors can view on-line submissions for marking and include comments that are then posted for the students. The system keeps track of who logs on when and for how long, as well as who has posted to discussion boards, taken quizzes, etc.

Despite the advantages, the current on-line courseware environment used at the University of Waterloo does not afford the type of collaborative environment that we believe to be of most benefit to student teams. While an instructor can group students together into virtual teams, teamwork is limited to discussion boards. There is no easy way for instructors to permit selected viewing of team documents or discussions by other classmates. Currently, instructor feedback to one group must be copied and pasted to all groups if the entire class is to benefit from a comment to a specific team; a tedious exercise when there are a number of teams in the class. Another disadvantage of UWOne is its current "Big Brother" approach to logging activity. The system monitors and records participation on all discussion boards. Students cannot turn such features off - as a result many discussions are stilted and overly formal, or non-existent, as students worry that every single contribution will be highly scrutinized by the instructor. It is this latter complaint that has lead students to use third-party solutions in order to keep some communications and preliminary ideas private; they then complain that they have to do double the work as they still have to upload submissions for grading.

We are designing STeamER to be a common space for team members and design teams and their instructors to share ideas and promote learning while still maintaining control over information that they choose to allocate to private and public spaces. Figure 1 illustrates the proposed architecture for software application. The electronic design space must meet the following requirements:

- Allow instructors to provide guidance on design process and methods, specification and implementation of project deliverables, and overall project management;

- Allow students to work both separately and collaboratively on design team projects;

- Allow students to view work of other team members and provide feedback when authorized; and

- Allow instructors to view different levels of project activity (class, teams, individuals) so as to provide timely feedback 


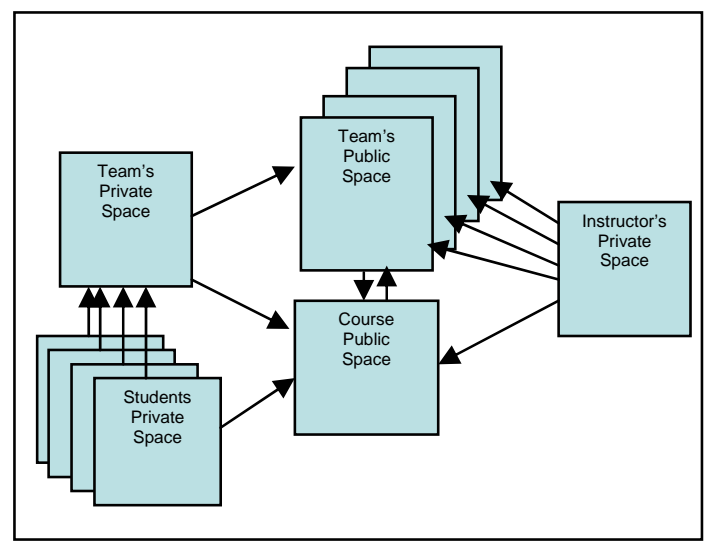

Figure 1. STeamER: public \& private spaces.

The private electronic spaces of students and instructors may reside on their personal computers, in personal account on a university server, or on other electronic media storage devices. Only designated members of a team have access to the team private space. Here is where student team members can have informal discussions and post rough drafts of sketches and ideas that are not meant to be shared outside the group. At any time, individual members of the team can move copies of private material into the team private space or into the team public space. The team public space is the view portal for the instructor. The instructor can comment on preliminary postings and submissions that have been voluntarily placed in the team's public space. In addition, the instructor can request that the team place preliminary work on the team's public for progress checks. Besides containing course documents (e.g. lecture notes, etc), the course public space can allow for "snapshots" of work across teams. We envision that this will allow the instructor to quickly assess whether a team has fallen behind and needs more directed guidance. In addition, this feature will allow teams to see how they are doing in comparison to other teams in the course.

\section{Addressing Student Team Needs}

Differentiating between private and public space will not by itself address common roadblocks for successful team performance. Based on our experience and our preliminary design work we discuss possible solution to two common problems faced by student teams: poor time management, and lack of trust.

\section{Why do Gantt charts not work for students?}

First year engineering students need particular help with managing time commitments beyond just the course project. Commercially available software applications, like Microsoft ${ }^{\circledR}$ Project, may be helpful for scheduling and tracking task completion in large projects, but such applications tend to be cumbersome and have steep learning curves for term-based student projects. In addition, commercial project management applications are not geared for providing feedback and instruction to novice design teams on the development of teamwork skills. Novice teams tend to have difficulty meeting project deadlines; largely because the members tend to underestimate how much time it will take to complete tasks - especially when done in a group. Students with little team experience often express dismay at the fact that it takes them longer to do a task as a group than it might have taken them to do the tasks as individuals. At the same time, they will often concede that the ideas generated by the group were more creative or more sophisticated than what might have been produced by an individual. Balancing off what needs to be done with available time and acceptable effort is a skill that needs to be developed.

We have found that while traditional Gantt charts are helpful in tracking activities of a single project, novice teams often overlook the fact that they have to meet the demands of the project in concert with the demands of other courses. We have found that getting students to map out deadlines using a calendar first makes it easier for them to produce more realistic Gantt charts. One of the features we are building into STeamER is a calendar-based project management tool that can be used by the team to include additional impedances to task deadlines that may be experienced by various members of the team. Allowing instructors to view team calendars should also allow for better feedback on project and task scheduling, as the instructor will be in a better position to gage how long tasks are likely to take than are first year engineering students. The scheduling rule of thumb used by consultant "multiple expected time to complete tasks by 3 " makes much more sense to students when they view a project task in the context of not only their own personal commitments but also in the context of the personal commitments of their team mates.

\section{Why is trust a problem?}

Besides time management, issues of trust are often major hurdles to success for novice teams. A common problem among novice teams is the belief that they should be together to discuss and agree on every detail of the project. Over involvement in a project can be as detrimental to team performance as under involvement. Over involvement can be a sign that teams do not know how to allocate tasks and make good use of resources including personnel, or 
that the team does not trust one another to do the work necessary for the betterment of the team. One way to encourage trust is to heighten accountability through collaborative space. Software techniques are available that allow team documents to be "signed out" for editing with new additions and changes flagged for team mates. At the same time, students posting to a course site must feel that their personal work is protected and cannot be sabotaged by others. The use of public and private space should increase feelings of security around personal work. We are experimenting with graphical displays of team participation and contributions that can be presented to students and instructors.

\section{Implementation ideas for STeamER}

In concert with the design and development of the user interactions, we have been wrestling with the implementation requirements for the STeamER software development. Since a secondary goal of STeamER is to experiment with new teaching ideas, a large part of of the user display and interaction may revolve around presenting information in more graphical fashion to the students. This will be particularly true for those areas, such as the team "corkboard" where we want to encourage creativity. Thus, the requirements for the user interface for the application are likely to be demanding so flexibility is important. Traditional programming tools such as Microsoft ${ }^{\circledR}$ Visual C++ do not allow for easy coding of the kind of interaction design that would be ideal for STeamER. For example, the main screen is envisioned to have animated transitions when the user clicks on new sections. This kind of animation is not easily coded using $\mathrm{C}++$ programming.

We have experimented with using Macromedia ${ }^{\circledR}$ Flash for preliminary mockups of the student interface that were shown to focus groups. Macromedia ${ }^{\circledR}$ Flash is a versatile toolkit that allows for very easy development of user interfaces and interaction designs that are graphically intensive. Another advantage of using Macromedia ${ }^{\circledR}$ Flash is that it has strong support for server based applications. It is relatively easy to implement a client program that transfers data with a backend server-side application securely. Furthermore, since Macromedia ${ }^{\circledR}$ Flash has strong support for XML, it is easy to transfer virtually any kind of information in a modularised manner. However, Macromedia®Flash was designed primarily for web content. Thus, it may not have the required low-level access to the client computer's hardware resources for features such as file management, and drag and drop features. This needs to examined in closer detail to determine whether this development platform is truly suitable for STeamER.
1. STeamER software within the next 2-3 years. We
understand that Microsoft ${ }^{\circledR}$ is planning to release an application development toolkit that is codenamed Sparkle $^{\mathrm{TM}}$, within 2 years as well. Sparkle is to combine the flexibility in interface design offered by programs such as Macromedia ${ }^{\circledR}$ Flash, with the low level access from traditional programming environments such as Visual $\mathrm{C}++$. Thus, it is conceivable that Sparkle could be used in the later prototyping stages for STeamER.

2.

\section{Looking Forward}

Through the progress of the STeamER project we hope to share the practical knowledge we have gained through working with student design teams. We are discussing with the University of Waterloo's Office of Research ethical ways of conducting research into team work and team development using the STeamER software. It is our hope that through the STeamER project we will contribute to the research side of engineering education as well as to practical instruction on teamwork and engineering design.

\section{References}

[1] M.E. Hacker and B.M. Kleiner, Identifying critical factors impacting virtual work group performance. In Proceedings of the International Engineering Management Conference, Institute for Electric and Electronic Engineers (IEEE), pp. 196-200, Piscataway, NJ: 1996.

[2] M. Mastromatteo, Team Player. Engineering Dimensions, vol. 25, no. 3, pp. 38-40, 2004.

[3] J. Kilker, Conflict on Collaborative Design Teams. IEEE Technology and Society Magazine, Fall, pp 12-21, 1999.

[4] D. Christiansen, ABET's EC2000, How're we doin'? IEEE-USA Today's Engineering, February 2002

[5] K. McMartin. The evolving role of the P.Eng: Is certification necessary? Engineering Dimensions, vol. 25, no. 3, pp. 34-36, 2004.

[6] K.L, Gentili, J.F. McCauley, R.K. Christianson, D.C. Davis, M.S.Trevisan, and D.E. Calkins, D.E. Assessing Students' Design Capabilities in an Introductory Design Class, In 29th ASEE/IEEE Frontiers in Education Conference, San Juan, Puerto Rico, Nov 10-13, 1999.

[7] Criteria for Accrediting Engineering Programs. Effective for evaluations of the 2004-2005 Accreditation Cycle. ABET Engineering Accreditation Commission, Baltimore MD: ABET 2003. http://www.abet.org Accessed May 10, 2004. 
[8] Canadian Engineering Accreditation Board Accreditation Criteria and Procedures 2003. Canadian Council of Professional Engineers. Accessed May 10, 2004.

http://www.ccpe.ca/e/files/report ceab.pdf

[9] C. MacGregor and L. Carson. Mentor-managed design challenges for First Year Engineering. Proceedings of the CDEN/RCCI Inaugaral Design Conference, Montreal, July 29-30, 2004.

[10] W.R. Cluett, W.R. Engineering Education for the $21^{\text {st }}$ Century: changing curriculum at the University of Toronto, Engineering Dimensions, vol 24, no. 4. pp 37-39, 2003

[11] J.S. McKee and F. Berruti, F. Engineering the Future. Engineering Dimensions, vol 24, no 4, pp 40-42, 2003

[12] K. Smith Teamwork and Project Management, second edition. Boston: McGraw-Hill, 2003.

[13] R. Pimmel, A practical approach for converting group assignments into team projects. IEEE Transactions on

Education, vol 46, no. 2, pp 273-282, 2003 